\title{
Phospholipase D1-Promoted Release of Tissue Plasminogen Activator Facilitates Neurite Outgrowth
}

\author{
Yan Zhang, ${ }^{1}$ Yasunori Kanaho, ${ }^{3}$ Michael A. Frohman, ${ }^{1,2}$ and Stella E. Tsirka ${ }^{1}$ \\ ${ }^{1}$ Program in Molecular and Cellular Pharmacology, Department of Pharmacological Sciences, and ${ }^{2}$ Center for Developmental Genetics, University Medical \\ Center at Stony Brook, Stony Brook, New York 11794, and ${ }^{3}$ Department of Pharmacology, Tokyo Metropolitan Institute of Medical Science, Tokyo 113-
}

8613, Japan

Temporal lobe epilepsy (TLE) is the most common form of epilepsy, affecting $\sim 1-2 \%$ of the population. Seizure events resulting from TLE are characterized by aberrant hippocampal mossy fiber sprouting and plastic responses that affect brain function. Seizure susceptibility is modulated by the enzyme tissue plasminogen activator (tPA), the normal physiological role of which includes promotion of synaptic reorganization in the mossy fiber pathway by initiating a proteolytic cascade that cleaves extracellular matrix components and influences neurite extension. tPA is concentrated at and selectively secreted from growth cones during excitatory events. However, the mechanisms underlying tPA release during seizure-induced synaptogenesis are not well understood. We examine here potential roles for the signaling enzyme phospholipase D1 (PLD1), which promotes regulated exocytosis in non-CNS cell types, and which we previously demonstrated increases in expression in hippocampal neurons during seizure-induced mossy fiber sprouting. We now show that overexpression of wild-type PLD1 in cultured neurons promotes tPA release and tPA-dependent neurite extension, whereas overexpression of an inactive PLD1 allele or pharmacological inhibition of PLD1 inhibits tPA release. Similarly, viral delivery of wild-type PLD1 into the hippocampus facilitates tPA secretion and mossy fiber sprouting in a seizure-inducing model, whereas the inactive PLD1 allele inhibits tPA release and elicits blunted and abnormal mossy fiber extension similar to that observed for tPA ${ }^{-1-}$ mice. Together, these findings suggest that PLD1 functions endogenously to regulate $\mathrm{tPA}^{-/-}$secretion and thus mossy fiber extension in the setting of elevated neuronal stimulation, such as that seen in TLE.

Key words: serine protease; phospholipids; neuroplasticity; secretion; hippocampus; mossy fiber

\section{Introduction}

Temporal lobe epilepsy is a common type of epilepsy (Engel et al., 1997). After epileptogenic injuries, dentate granule cell axons [mossy fibers (MF)] sprout and form new synaptic connections (Parent and Lowenstein, 1997; Represa and Ben-Ari, 1997). This aberrant synaptogenesis generates recurrent excitatory circuits that affect brain functioning (Buckmaster et al., 2002). Tissue plasminogen activator (tPA) is an extracellular serine protease involved in the pathological excitation of glutamate receptorexpressing neurons (Qian et al., 1993; Nicole et al., 2001). tPA activates plasminogen to plasmin by proteolytic cleavage; plasmin degrades extracellular matrix (ECM) components such as chondroitin sulfate proteoglycans and influences neurite extension, sprouting, and synaptic reorganization in the MF pathway (Wu et al., 2000). tPA is focally concentrated at and selectively secreted from neuronal growth cones during excitation (Krystosek and Seeds, 1981; Pittman, 1985; Verrall and Seeds, 1988).

Received July 14, 2004; revised Jan. 3, 2005; accepted Jan. 5, 2005

This work was supported by grants from the National Institutes of Health to S.E.T. and M.A.F. We thank members of the Tsirka and Frohman laboratories and Dr. Joel Levine for helpful suggestions.

Correspondence should be addressed to Dr. Stella E. Tsirka, Department of Pharmacological Sciences, University Medical Center at Stony Brook, Stony Brook, NY 11794-8651. E-mail: stella@pharm.sunysb.edu. DOl:10.1523/JNEUROSCI.4850-04.2005

Copyright $\odot 2005$ Society for Neuroscience $\quad$ 0270-6474/05/251797-09\$15.00/0
However, the molecular mechanisms that regulate tPA release from the growth cone after epileptiform events await elucidation.

The signaling enzyme phospholipase D (PLD), which hydrolyzes phosphatidylcholine (PC) to generate phosphatidic acid (PA), plays important roles in exocytosis, phagocytosis, membrane trafficking, and cytoskeletal dynamics (Liscovitch et al., 2000; Cockcroft, 2001; McDermott et al., 2004). Two mammalian PLD genes, PLD1 and PLD2, exist and have been characterized at the molecular level (Frohman et al., 1999). Both enzymes are upregulated in response to extracellular agonist signals, neurotransmitters, growth factors, hormones, and cytokines. PLD1 has been linked to regulation of secretion and secretory granule exocytosis (Chen et al., 1997; Vitale et al., 2001; Choi et al., 2002; Hughes et al., 2004), whereas PLD2 plays a more obvious role in regulation of cell morphology and endocytosis (Colley et al., 1997; Honda et al., 1999; Du et al., 2004).

In-culture and in vivo studies have suggested a role for this enzyme in the modulation of neurite outgrowth. PLD expression and activity have been reported to increase during neuronal differentiation of the rat pheochromocytoma cell PC12 and the immortalized mouse hippocampal stem cell HiB5 (Hayakawa et al., 1999; Min et al., 2001; Sung et al., 2001), and blocking PLD activation significantly inhibited neurite outgrowth. PLD1 and PLD2 have been reported to be expressed in PC12 cells (Hayakawa et al., 1999); however, the pattern of expression differs in different sub- 
lines (Gibbs and Meier, 2000). Establishing relevance for the in vivo setting, we found in mice that neurons express PLD1 and astrocytes express PLD2. Both proteins undergo expression upregulation during hippocampal MF sprouting (Zhang et al., 2004). These findings prompted us to investigate the role of neuronally expressed PLD1 on neurite growth and the underlying mechanism through which it functions.

In this study, we demonstrate that overexpression of wild-type PLD1 enhances tPA secretion both in cultured primary hippocampal neurons and in the brain, whereas overexpression of catalytically inactive PLD1 or pharmacological diversion of PLD activity is inhibitory. We also report that overexpression of wildtype PLD1 potentiates hippocampal MF outgrowth, whereas competitive inhibition of endogenous PLD1 by overexpression of the inactive allele blunts MF outgrowth, identifying a new regulatable step in the process.

\section{Materials and Methods}

Generation of Sindbis pseudovirions. Sindbis pseudovirions were generated using the Sindbis Expression kit. cDNA fragments encoding wildtype PLD1 and the catalytic-inactive PLD1 (K898R) open reading frames were subcloned into the Sindbis virus backbone vector pSinRep5. Both constructs were tagged with enhanced green fluorescent protein (EGFP) at the $\mathrm{N}$ terminus. Linearized DNA was used to produce capped mRNA that lacked the structural components of the virus; these were generated separately in a second transcription procedure with the helper virus plasmid $(\mathrm{pDH})$. Construct and helper mRNAs were transfected into baby hamster kidney cells to generate replication-defective pseudovirions. Twenty-four hours later, the conditioned medium containing viral particles was collected for infection of experimental cells. Three different preparations were generated: SIN-EGFP, SIN-EGFP-PLD1, and SIN-EGFP-PLD1(K898R).

Primary cell culture. Primary hippocampal neuronal cultures were prepared as described previously (Rogove and Tsirka, 1998). Briefly, hippocampi from embryonic day 17-19 mouse embryos were dissected and gently trypsinized $(0.25 \%$ trypsin in $\mathrm{HBSS})$ at $37^{\circ} \mathrm{C}$ for $15 \mathrm{~min}$ and then triturated to form single-cell suspensions. The cells were plated onto poly-D-lysine-precoated tissue culture plates in Neurobasal medium with B27 supplements, $25 \mu \mathrm{M}$ glutamate, $0.5 \mathrm{~mm}$ L-glutamine, and 10 $\mu \mathrm{g} / \mathrm{ml}$ gentamycin sulfate. The medium was changed $3 \mathrm{~h}$ after the initial plating, and the glutamate was removed after $4 \mathrm{~d}$ in culture. After 7-10 d in culture, the neurons were infected with Sindbis pseudovirions for $10 \mathrm{~h}$. SIN-EGFP served as the negative control for viral infection.

Determination of length of neurites. To measure neurite length, dissociated hippocampal neurons from C57BL/6 (wild type) and tPAdeficient $\left(\mathrm{tPA}^{-/-}\right.$) mice were plated on 18 -mm-round coverslips at a density of $10^{4}$ cells per coverslip. After $2 \mathrm{~d}$ in culture, the neurons were infected with Sindbis pseudovirions for $4 \mathrm{~h}$, washed with Neurobasal medium, and incubated in regular culture medium overnight. Twentyfour hours later, cells were fixed in $4 \%$ paraformaldehyde $/ 4 \%$ sucrose in PBS and mounted with VECTASHIELD HardSet mounting medium (Vector Laboratories, Burlingame, CA) for fluorescent microscopic analysis. The sections were examined using a Nikon (Tokyo, Japan) PCM 2000 confocal microscope. The images were captured, and neurite length was measured using SPOT RT software (SPOT Diagnostic Instruments, Sterling Heights, MI). A total of 60 neurons per group were analyzed by an observer blinded to the experimental treatment.

Quantitative Western blot. Virus-infected neurons were collected in PBS containing protease inhibitor mixture (Sigma, St. Louis, MO) and lysed by brief sonication. Total protein concentration was measured using the Bradford detergent-compatible assay (Bio-Rad, Hercules, CA). Equal amounts $(4 \mu \mathrm{g})$ of protein from each sample were separated on a $8 \%$ SDS-polyacrylamide gel, transferred onto polyvinylidene difluoride membrane, blocked with 5\% nonfat dry milk in PBS/0.1\% Tween 20 (PBS-T), incubated with anti-PLD1 antibody (affinity-purified polyclonal; 1:3000 dilution) (Zhang et al., 2004) overnight in PBS-T/5\% bovine serum albumin, and visualized using Alexa Fluor-488-conjugated secondary antibody (1:1000 dilution; Molecular Probes, Eugene, OR). Fluorescence was detected by a FluorImager (Molecular Devices, Menlo Park, CA) and quantified using ImageQuant software (Amersham Biosciences, Sunnyvale, CA). Anti-actin (mouse monoclonal, 1:1500; ICN Biomedicals, Shelton, CT) was used to confirm equal loading of proteins.

$t P A$ secretion assay. After infection with Sindbis virus, hippocampal neurons were washed and incubated with Neurobasal medium for $1 \mathrm{~h}$. Some neurons were treated with $0.5 \%$ 1-butanol or $0.5 \%$ 3-butanol in Neurobasal medium for $1 \mathrm{~h}$. Later, neurons were washed with Tyrode's buffer [pH 7.4, consisting of (in mM) $119 \mathrm{NaCl}, 5 \mathrm{KCL}, 4 \mathrm{CaCl}_{2}, 2 \mathrm{MgCl}_{2}$, 30 glucose, and 20 HEPES]. The cells were then exposed to $50 \mu \mathrm{M}$ forskolin (Sigma) or $10 \mu \mathrm{M} \mathrm{Ca}{ }^{2+}$ ionophore A23187 (Sigma) diluted in Tyrode's buffer. Some neurons were additionally treated with $0.5 \%$ 1-butanol or $0.5 \%$ 3-butanol. The supernatant was collected at different time intervals, and the tPA concentration was measured by ELISA using an anti-mouse tPA antibody (monoclonal, 1:12,500; Molecular Innovations, Southfield, MI). The secreted tPA amount was calculated and normalized to total protein concentration.

Animal preparation and surgery. Animals were maintained in the Stony Brook Department of Laboratory Animal Research. All procedures followed guidelines set by the National Institutes of Health and were approved by Stony Brook University.

Intra-amygdaloid kainic acid (KA) injection was performed on adult male wild-type and $\mathrm{PPA}^{-1-}$ mice, age matched and weighing $\sim 20 \mathrm{~g}$, as described previously (Niquet et al., 1993; Wu et al., 2000). Mice were given intraperitoneal injections of atropine $(0.6 \mathrm{mg} / \mathrm{kg}$ body weight $)$, anesthetized deeply with $2.5 \%$ avertin $(0.02 \mathrm{ml} / \mathrm{g}$ body weight), placed in a stereotaxic apparatus, and given a unilateral injection of $1.5 \mathrm{nmol}$ of KA (Sigma) in $0.3 \mu \mathrm{l}$ of PBS into the amygdala. The coordinates of the injection were as follows: bregma, $-1.6 \mathrm{~mm}$; mediolateral, $3.3 \mathrm{~mm}$; dorsoventral, $4.5 \mathrm{~mm}$ (Franklin and Paxinos, 1997). KA was delivered over 1 $\mathrm{min}$. After the delivery, the injection needle remained at the above coordinates for another $5 \mathrm{~min}$ to prevent reflux of fluid. After KA injection, a mini-osmotic pump (Alzet model 1007D; Durect, Cupertino, CA) containing $100 \mu \mathrm{l}$ of Sindbis virus suspension was placed subcutaneously in the back of the animal. A brain-infusion cannula connected to the pump was positioned at coordinates bregma $-1.8 \mathrm{~mm}$, mediolateral $+1.1 \mathrm{~mm}$, and dorsoventral $2.5 \mathrm{~mm}$ to deliver the virus near the dentate gyrus (DG) of the hippocampus. The infusion rate was $0.5 \mu \mathrm{l} / \mathrm{h}$. The pump was allowed to infuse the designated solution for 4 or $7 \mathrm{~d}$. SIN-EGFP served as the negative control. Animals that were used for subsequent experiments ( $n=8$ for each treatment) displayed seizures scored as 2 or 3 , based on the scale described below. The seizure severity was quantified using a five-point observer rating scale, as described by Royle et al. (1999): $0=$ normal behavior; 1 = rare wet dog shakes (WDS) and rare convulsions affecting the head and extremities, typically starting within $30 \mathrm{~min}$ of KA administration; 2 = frequent WDS and convulsions affecting the head and extremities (no rearing); 3 = frequent head and extremities convulsions with appearance of generalized tonic-clonic seizures usually starting between 60 and $90 \mathrm{~min}$ after $\mathrm{KA}$ administration with rearing; $4=$ frequent generalized tonic-clonic seizures with falling; $5=$ continuous, generalized limbic seizures and death within $3 \mathrm{~h}$. No recurrent seizures were evident in the mice beyond the first day after the KA injection. Animals were killed 4, 7, or $15 \mathrm{~d}$ after KA injection.

Histochemistry and immunofluorescent microscopy. Animals were perfused transcardially with $0.2 \%$ sodium sulfide, after which their brains were removed and freshly frozen. Coronal brain sections $(30 \mu \mathrm{m})$ at the level of the hippocampus were prepared on a cryostat at $-15^{\circ} \mathrm{C}$ (Leica CM 1900; Leica Microsystems, Bannockburn, IL). MFs were stained according to a modified Timm silver staining method (Holm and Geneser, 1991). GAP-43 (mouse monoclonal, 1:500; Sigma) staining was performed to show newly formed sprouts, detected with cyanine 3 (Cy3)conjugated secondary antibodies (1:1000; Jackson ImmunoResearch, West Grove, PA). For visualization of the general histology in the hippocampi, sections were stained for $30 \mathrm{~min}$ in $0.5 \%$ cresyl violet solution. To trace the expression of EGFP-tagged proteins in the brain, sections were fixed with $4 \%$ paraformaldehyde/ $4 \%$ sucrose in PBS and then mounted with Vectashield mounting medium (Vector Laboratories) for fluorescent microscopic analysis. To confirm neuronal expression of 
a.

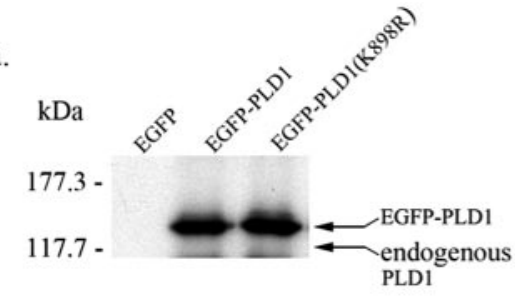

b.

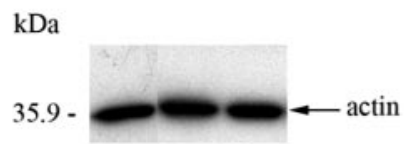

c.

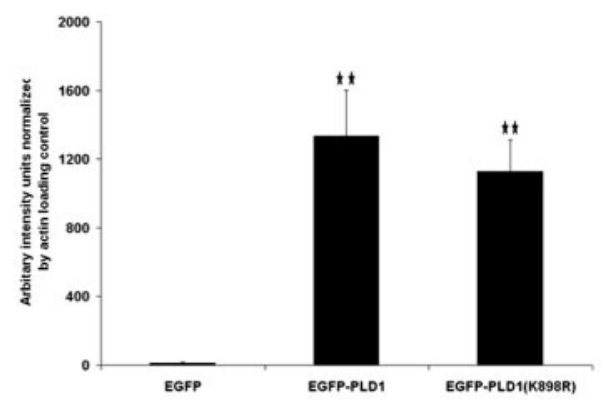

Figure 1. Expression of EGFP-tagged PLD1 and its catalytically inactive mutant PLD1(K898R) in mouse primary hippocampal neurons. Cultured C57BL/6 mouse hippocampal neurons were infected with viral vectors encoding EGFP, EGFP-PLD1, or EGFPPLD1(K898R). Ten hours later, total cell lysates were collected, and equal amounts $(4 \mu \mathrm{g})$ of protein were separated on $8 \%$ SDS-PAGE. PLD1 was detected by quantitative Western blot using a polyclonal anti-PLD1 antibody. $\boldsymbol{a}$, Representative Western blot; equal loading of proteins was confirmed by anti-actin Western blotting (b). c, Quantification of PLD1 expression normalized to actin. Neurons do express endogenous PLD1 protein that migrates faster (121 kDa) than EGFP-PLD1 (144 kDa); however, it was not detected in this Western blot because of the small amount of protein loaded on the gel as per optimal conditions for detecting the overexpressed fusion proteins. Experiments were performed in quadruplicate. ${ }^{* *} p<0.01$ compared with EGFP-expressing control cells.

these transgenes, the same brain sections were also stained with primary antibodies against a neuronal marker protein, neuron-specific nuclear protein (NeuN; mouse monoclonal, 1:500; Chemicon, Temecula, CA) and then detected with Cy3-conjugated secondary antibodies (1:1000; Jackson ImmunoResearch). The sections were examined using a Nikon PCM 2000 confocal microscope. Images were captured by an observer blinded to the experimental treatment. Quantitation of Timm stain was performed using Scion Image software (Scion Corporation, Frederick, MD). Timm granules were measured in the DG and CA3 regions using the Scion software and normalized by surface area (and length of the DG), as described by Zheng et al. (1998).

In situ zymography. Coronal brain sections $(30 \mu \mathrm{m})$ were overlaid with a mixture consisting of $1 \%$ low-melting point agarose, $1 \mathrm{mg} / \mathrm{ml}$ plasminogen, $1 \mathrm{~mm}$ amiloride (a selective urokinase inhibitor), $0.1 \mathrm{~mm}$ Tris- $\mathrm{Cl}$, $\mathrm{pH} 7.5$, and $2.5 \%$ nonfat dry milk. The sections were coverslipped to even the overlay and then incubated at $37^{\circ} \mathrm{C}$ in a humidified chamber. tPA activity was visualized as degradation of casein (a clearing of the overlay) by the activation of plasminogen into plasmin. The grayscale image was converted to pseudocolor using SimplePCI software (C-Imaging Systems, Compix; Cranberry Township, PA) for better visualization of the zymography images.

Statistical analysis. Quantitative data are presented as mean $\pm \mathrm{SD}$. The sample size is indicated in the corresponding experimental methods, results, or figure legends. Statistical analysis was performed using $t$ test and one-way ANOVA with LSD post hoc analysis, as appropriate.

\section{Results}

tPA secretion from neurons is potentiated by wild-type PLD1 and suppressed by a catalytically inactive allele

To study directly the effects of neuronally expressed PLD1 on tPA secretion, we introduced either wild-type PLD1 or a catalytically inactive mutant [PLD1(K898R)] into cultured primary hippocampal neurons via Sindbis viral infection. Neurons are among the most difficult cells to transfect using traditional methods. The recombinant Sindbis virus system has the advantage of high transfection efficiency and neurotropism. Ten hours after viral infection, the cells showed no visible signs of neurotoxicity, and the expression of transfected PLD1 was increased dramatically as detected by quantitative Western blotting (Fig. 1). Hippocampal neurons do express PLD1 (Zhang et al., 2004), but the low-abundance endogenous protein was not visualized with the short exposure times determined to be optimal for detecting the overexpressed proteins.

PLD1 is a highly regulated enzyme, typically exhibiting little to no activity in nonstimulated cells and dramatic activation in stimulated cells. To explore whether PLD1 overexpression alters regulated tPA secretion, we first examined the basal levels of tPA secretion from unstimulated neurons expressing EGFP, EGFP-PLD1, or EGFP-PLD1(K898R). No significant difference was observed, indicating that high expression of neither PLD1 nor PLD1(K898R) altered tPA secretion via toxic or nonspecific mechanisms. Stimulation of cultured rat hippocampal neurons by $50 \mu \mathrm{M}$ forskolin has previously been reported to induce tPA secretion, which is followed by formation of varicosities and axonal elongation (Baranes et al., 1998). After forskolin stimulation, the secretion of tPA from neurons expressing EGFP-PLD1 increased twofold compared with cells expressing just EGFP (Fig. 2a), whereas those expressing catalytically inactive PLD1 exhibited a small decrease. These results suggest that PLD1 activation is a rate-limiting event in forskolin-triggered tPA secretion by neurons, although it may underestimate the role of PLD1 because forskolin is not a traditional PLD stimulator (Mamoon et al., 1999). The catalytically inactive (dominant-negative) approach was further supported by pharmacological inhibition of PLD1 using 1-butanol, a primary alcohol that inhibits PLD signaling by competitively diverting the production of phosphatidic acid to phosphatidyl-butanol (McDermott et al., 2004). PLD1enhanced tPA secretion as stimulated by forskolin was attenuated in the presence of $0.5 \%$ 1-butanol but not completely ablated (Fig. 2a). This partial decrease was likely because of the relatively low amount of 1-butanol used, because PLD1 activity is not totally inhibited at this concentration (Skippen et al., 2002). Higher concentrations of 1-butanol that could fully block PLD1 activity were not used, because they can elicit toxicity (Skippen et al., 2002). In contrast, $0.5 \%$ 3-butanol, a tertiary alcohol that does not serve as a substrate for the transphosphatidylation reaction catalyzed by PLD, was less able to inhibit tPA release (Fig. 2a). Even greater tPA release was observed for neurons stimulated by $10 \mu \mathrm{M} \mathrm{Ca}^{2+}$ ionophore A23187, which is a potent activator of PLD1 (Siddiqi et al., 2000), and this increase was again inhibited to a greater extent by 1-butanol than by 3-butanol (Fig. 2b). Finally, control neurons also exhibited a decrease in ionophoretriggered tPA secretion in the presence of 1-butanol (Fig. 2c), suggesting that endogenous neuronal PLD1 facilitates tPA release. Together, these data indicate that in cultured primary hippocampal neurons, PLD1 mediates tPA secretion through mechanisms dependent on its catalytic activity.

\section{Promotion of neurite extension by PLD1 overexpression}

We next set out to examine whether PLD1-facilitated release of tPA altered neurite extension. Secretion of tPA has been shown to be essential for neurite sprouting both in vivo and in vitro (Garcia-Rocha et al., 1994; Wu et al., 2000; Parmar et al., 2002); therefore, proteins that modulate tPA secretion could influence neurite extension as well. We measured the length of neurites of 
a.

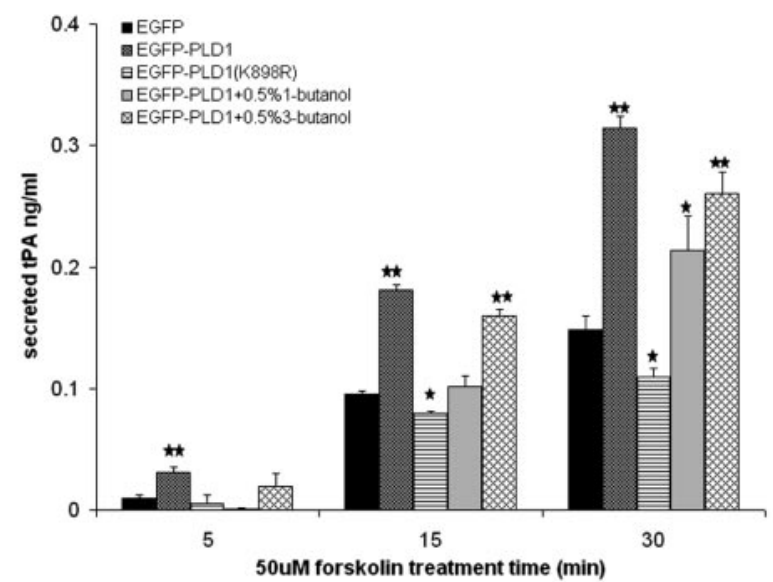

b.

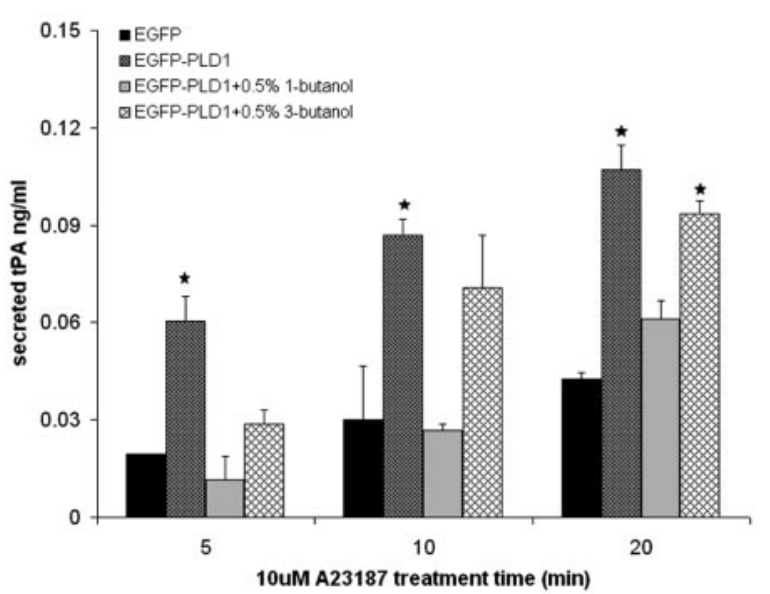

c.

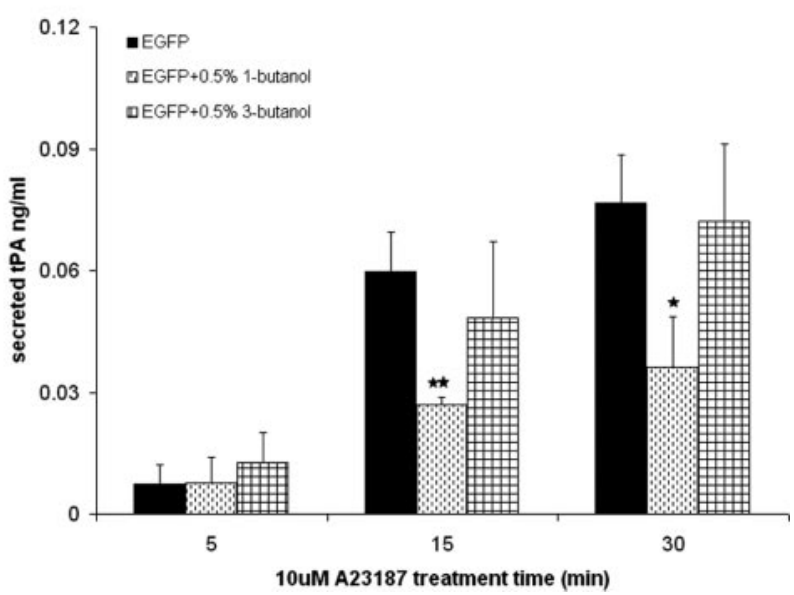

Figure 2. PLD1 facilitates agonist-stimulated tPA secretion from hippocampal neurons in an

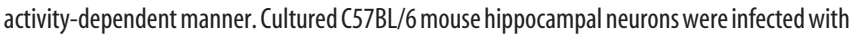
Sinbis viral vectors as described above and then challenged with $50 \mu \mathrm{m}$ forskolin $(\boldsymbol{a})$ or $10 \mu \mathrm{M}$ $\mathrm{Ca}^{2+}$ ionophore A23187 $(\boldsymbol{b}, \boldsymbol{c})$ for different time intervals. A total amount of $0.5 \%$ 1-butanol or $0.5 \% 3$-butanol was additionally present in some wells. Neurons in $\boldsymbol{a}$ and $\boldsymbol{b}$ were overexpressing either wild-type or mutant PLD1; neurons in c were expressing only endogenous levels of PLD1. Conditioned medium was collected and analyzed by ELISA for TPA content. The amount of secreted tPA in the culture medium was normalized to the total protein concentration. Experiments were performed in triplicate and analyzed by ANOVA. ${ }^{*} p<0.05$; ${ }^{* *} p<0.01$ compared with EGFP-expressing control cells. a.

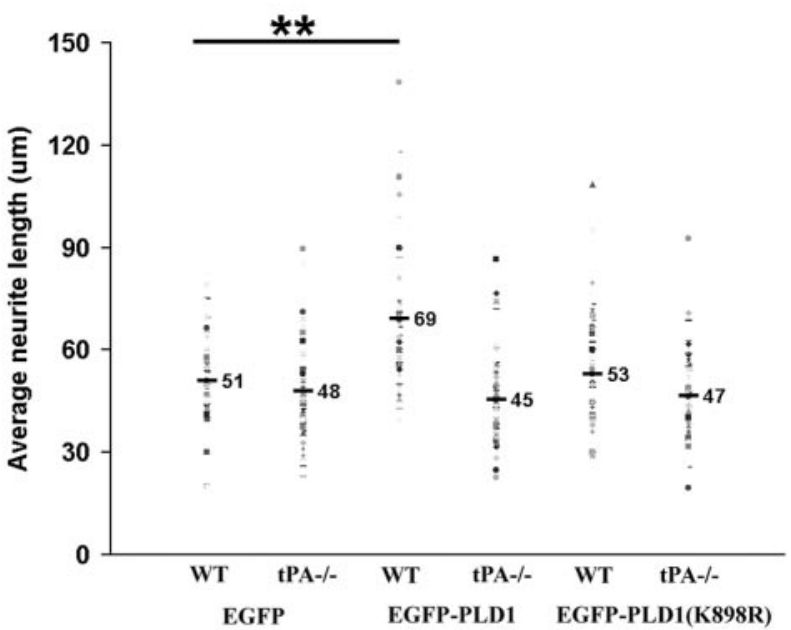

b.

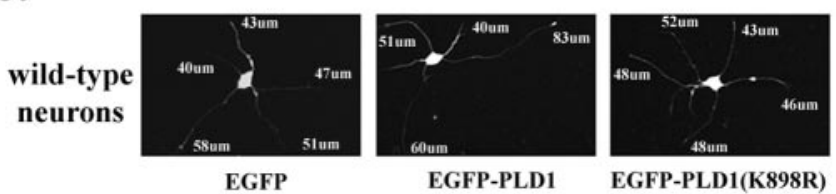

Figure 3. PLD1 promotes neurite extension from cultured wild-type mouse hippocampal neurons. Two days after being plated in culture, dissociated wild-type and tPA ${ }^{-1-}$ mouse hippocampal neurons were infected with pseudovirions SIN-EGFP, SIN-EGFP-PLD1, or SINEGFP-PLD1(K898R). Successfully infected cells were identified via the presence of EGFP fluorescence. Twenty-four hours after infection, measurement of neurite length was performed on captured images of fixed cells using SPOT RT software. $\boldsymbol{a}$, Quantification of the neurite length of wild-type (WT) and tPA ${ }^{-1-}$ neurons. Neurite length is $51 \pm 13 \mu \mathrm{m}$ in neurons expressing EGFP, $69 \pm 21 \mu \mathrm{m}$ in neurons expressing EGFP-PLD1, and $53 \pm 17 \mu \mathrm{m}$ in neurons expressing the inactive PLD1 allele. $\boldsymbol{b}$, Representative images of individual wild-type neurons infected with the respective virions. The lengths of the neurites emanating from these neurons are shown. Sixty neurons from each condition were used to generate the pooled measurement and were analyzed by ANOVA. ${ }^{* *} p<0.01$ compared with EGFP-expressing control cells.

individual wild-type and $\mathrm{tPA}^{-1-}$ neurons from low-density cell cultures infected with PLD1-expressing and control virions (Fig. 3 ). The average neurite length of wild-type neurons overexpressing PLD1 was $69 \mu \mathrm{m}$, which was significantly longer than that of EGFP-expressing control cells $(51 \mu \mathrm{m})$. The effect of PLD1 was activity dependent, because no increase in neurite length was observed in cells infected with EGFP-PLD1(K898R) virus (53 $\mu \mathrm{m})$. EGFP-PLD1(K898R) did not function effectively as a dominant-negative isoform in this assay, potentially because the relatively small amount of inhibition of tPA release that occurred (Fig. 2a) was not sufficient to lead to a detectable suppression of neurite extension. Again, it should be noted that this assay probably underestimates the role of PLD1, because no deliberate stimulation of the enzyme took place under the culture conditions. On the other hand, overexpression of PLD1 in $\mathrm{tPA}^{-1-}$ neurons did not affect neurite length compared with control cells (Fig. $3 a$ ), demonstrating that TPA functions downstream of PLD1 to promote neurite growth and that PLD1 functions via a tPAdependent pathway.

Marked changes in TPA secretion and MF outgrowth with neuronal overexpression of PLD1 or PLD1(K898R) in the mouse hippocampus

It has been shown previously that extracellular tPA activity increases in the hippocampus after membrane depolarization, presumably as a consequence of being secreted (Gualandris et al., 

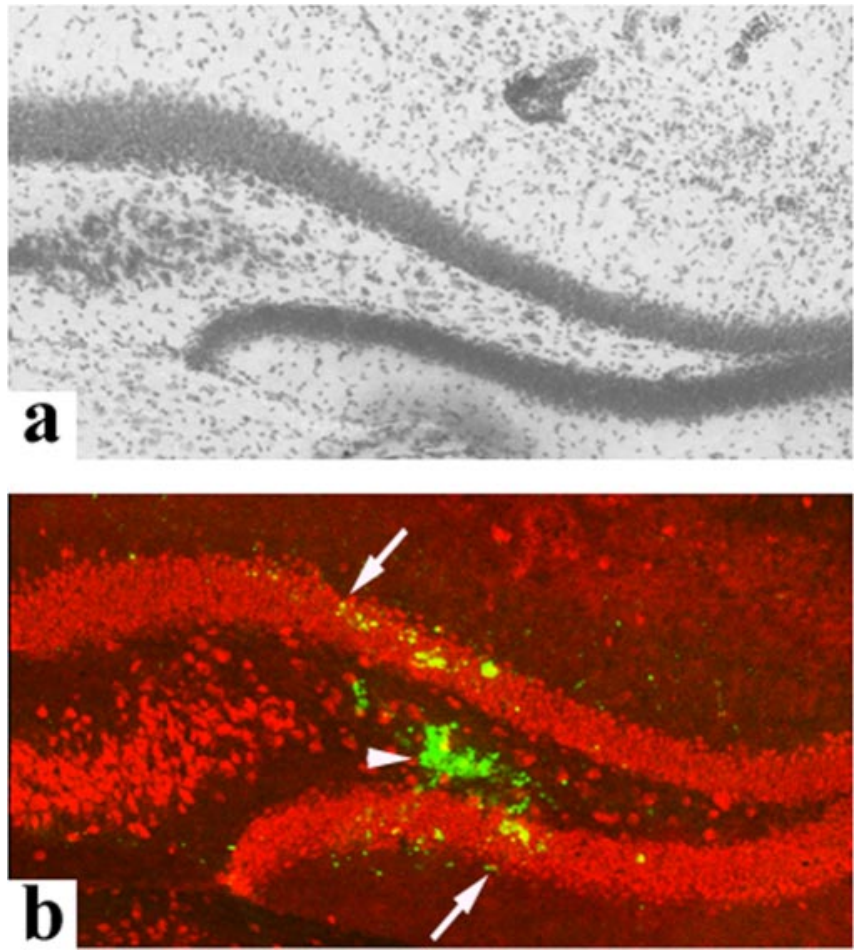

Figure 4. Expression of recombinant PLD1 in vivo at day 15 after intrahippocampal delivery of Sindbis pseudovirions. Recombinant Sindbis viral vectors encoding EGFP, EGFP-PLD1, or EGFP-PLD1(K898R) were delivered into the DG via mini-osmotic pumps in wild-type mice. Expression of the GFPs was examined in coronal brain sections of animals killed at day $15(\boldsymbol{b})$. Parallel brain sections were stained with cresyl violet to illustrate the locations of fluorescent signals inside the hippocampi $(\boldsymbol{a})$. EGFP fluorescence is detected focally around the site of infusion ( $\boldsymbol{b}$, arrowhead) and diffuses to a limited distance ( $\boldsymbol{b}$, arrows). The expression is confined to neurons as judged by costaining with the neuronal marker $\operatorname{NeuN}(\boldsymbol{b}$, red).

1996). Secreted tPA participates in hippocampal MF growth and remodeling via mechanisms dependent on and independent of its enzymatic activity (Wu et al., 2000). We therefore set out to investigate whether PLD1 contributes to neuronal tPA secretion and subsequent MF sprouting in the mouse hippocampus. Successful gene transfer into neurons via injection of Sindbis virions into different regions of the mouse brain, including the hippocampus, has been reported (Agapov et al., 1998; Chen et al., 2000; D’Apuzzo et al., 2001; Takahashi et al., 2003).

We further optimized delivery of PLD1 Sindbis virus into the mouse hippocampus by using micro-osmotic pumps. Figure $4 b$ illustrates expression of recombinant EGFP-PLD1 [or PLD1(K898R)] in the DG on day 15 after the start of infusion. Infection was restricted to neurons within the virus-infused area. As judged from cell morphology based on cresyl violet stain (Figs. $4 a, 5 a$ ) and NeuN stain (Fig. 4b), no significant cell toxicity was discernible after viral infection, at least up to days 15 after infection. In situ tPA activity and MF outgrowth were followed over the $15 \mathrm{~d}$ time course after viral infection. Although the results in Figure 3 suggest that subtle alterations in MF morphology might be observed even in control mice, our previous findings indicated that tPA plays a more overt role in mice subjected to epileptic stimulation (Wu et al., 2000), and thus we examined both control and kainate-injected groups of mice. Kainate, a glutamate analog, stimulates tPA release and epileptic seizures and is well known as a PLD activator in the CNS (Holler et al., 1993; PellegriniGiampietro et al., 1996). The injection of excitotoxins has been shown to stimulate the quick secretion of tPA locally; in this

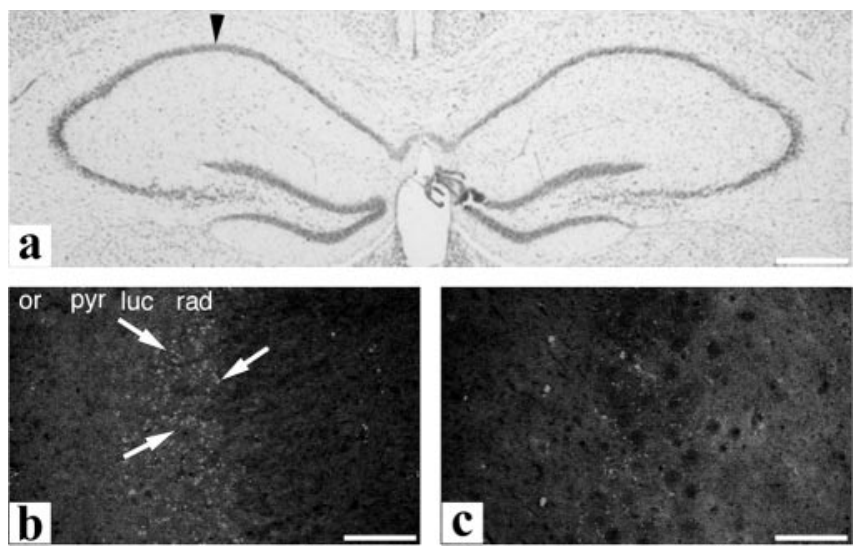

Figure 5. The presence of newly formed MF sprouts without overt neurodegeneration in the hippocampus. At day 15 after unilateral intra-amygdaloid kainate injection, cresyl violet stain shows intact neuronal layers throughout the hippocampus ( $\boldsymbol{a}$, injected side indicated). Punctate GAP-43 stain indicates the presence of newly formed MF sprouts in the ipsilateral CA3 area ( $\boldsymbol{b}$, arrows), whereas only background staining was seen in the contralateral CA3 area (c). or, Stratum oriens; pyr, stratum pyramidale; rad, stratum radiatum; luc, stratum lacunosum. Scale bars: $\boldsymbol{a}, 350 \mu \mathrm{m} ; \boldsymbol{b}, \boldsymbol{c}, 50 \mu \mathrm{m}$.

model, kainate is delivered distally (amygdala) to the area where MF sprouting and tPA secretion are visualized (hippocampus). Therefore a delay in monitoring of MF sprouting and tPA activity is necessary (Niquet et al., 1993). The punctate pattern of GAP-43 stain confirmed the presence of newly formed MF sprouts in the hippocampus at day 15 after intra-amygdaloid kainate injection (Fig. 5b).

Kainate injection into SIN-EGFP-infused wild-type mice elicited sprouting by day 15 on the ipsilateral side of the supragranular region of the DG but not on the contralateral side (Figs. $6 a-c$, $7 a, b)$. The changes observed were consistent with the extent of sprouting we and others have reported previously (Represa et al., 1987; Niquet et al., 1993; Wu et al., 2000). In contrast, marked increases in sprouting were observed on the ipsilateral side in kainate-injected wild-type mice infused with SIN-EGFP-PLD1 (Fig. 6d): exaggerated sprouts were evident in both the supragranular region of the dentate (Fig. $7 c$, arrows) and the strata infrapyramidale (Fig. $6 e$, asterisks) and oriens of the $\mathrm{CA} 3$ region (Figs. $6 e, 7 d$, arrows), especially in the stratum infrapyramidale, indicating the presence of robust axonal sprouting (quantitation of changes listed in Table 1). In a previous report (Zhang et al., 2004), we showed that PLD1 is upregulated after kainate delivery, and although the levels of increase achieved by PLD1 overexpression are higher than those achieved by the kainate injection, they point to a role of PLD1 in promoting neurite outgrowth.

Conversely, in wild-type mice infused with SIN-EGFPPLD1(K898R), there were locally distinct patterns of inhibited MF sprouting (Fig. $6 g$ ): in the CA3 region; the sprouts were mostly diminished, most notably in the stratum infrapyramidale (Figs. 6h, arrows, $7 f$, red arrows) (quantitation of changes is listed in Table 1), whereas in the dentate, the sprouts were blunted (Fig. $7 e$, red arrows) and formed aggregates of Timm-stained granules along the border between the supragranular region and the molecular layer (Fig. 7e, blue arrows). This phenotype is comparable with the pattern of MF sprouting described for $\mathrm{tPA}^{-1-}$ mice $(\mathrm{Wu}$ et al., 2000), as shown in Figure 7, $g$ and $h$, in which EGFP was delivered in kainate-stimulated $\mathrm{tPA}^{-1-}$ mice.

To explore whether the changes observed in the mice correlated with decreased tPA release, we performed in situ zymographic assays. In the unstimulated hippocampus of wild-type 
mice, tPA activity is concentrated along the MF pathway: the CA3 area and the hilus (Tsirka et al., 1995; Sallés and Strickland, 2002; Siao et al., 2002). With epileptic stimulation, tPA activity increases moderately along the MF pathway on the ipsilateral side, as seen in mice infected with SIN-EGFP day 7 after kainate injection (Fig. $8 a$, blue area outlined by arrows). With EGFP-PLD1 infusion, upregulation of secreted tPA activity was observed in the DG and CA3 on the stimulated side (Fig. $8 c$, arrows) compared with either the contralateral hippocampus of the same mouse (Fig. $8 d$, arrows) or the ipsilateral side of the kainate-injected, SIN-EGFP-infected hippocampus (Fig. $8 a$ ). In contrast, decreased tPA activity was detectable in the hippocampus infected with SIN-EGFP-PLD1(K898R) (Fig. 8e) compared with the contralateral side of the same animal (Fig. $8 f$, arrows) or either side of the control animals (Fig. 8a). Changes in MF growth were not detected in any of the experimental groups at day 7. Conversely, levels of secreted tPA were indistinguishable at day 15 (and change in neither MF growth nor secreted tPA activity was demonstrable at day 4). This separation in the time course of tPA secretion (day 7 ) and MF growth (day 15) is consistent with the hypothesis that $\mathrm{PAA}$ secretion precedes observable neurite growth.

To examine whether the effect of PLD1 expression on MF extension proceeds through a tPA-dependent pathway, we examined the outcome in $\mathrm{tPA}^{-1-}$ mice. A previous study from our group had demonstrated that kainate-stimulated $\mathrm{PA}^{-1-}$ mice exhibit diminished and aberrant MF sprouting because of deficits in the process of ECM remodeling (Wu et al., 2000).

Kainate-treated $\mathrm{PPA}^{-1-}$ mice expressing high levels of PLD1 displayed blunted, distorted sprouts (Fig. $6 d^{\prime}-f^{\prime}$ and data not shown) and a dense laminar band between the supragranular and molecular layers, comparable with that observed in $\mathrm{tPA}^{-1-}$ mice receiving control virion infusion (Fig. $7 g$, red and blue arrows). In addition, decreased neurite growth in the stratum oriens of the CA3 area (Fig. $6 e^{\prime}$, arrows) was evident in these mice compared with wild-type mice treated similarly (Fig. $6 e$, arrows). The different outcomes in MF outgrowth for the PLD1-overexpressing wild-type and $\mathrm{tPA}^{-/-}$mice demonstrate that the effect of PLD1 on MF growth is mediated through the action of tPA (i.e., lack of tPA leads to disorganized sprouting regardless of the PLD1 expression level). Expression of inactive PLD1 in the $\mathrm{PA}^{-/-}$hippocampus resulted in formation of intensely Timm-positive clusters in the DG (Fig. $6 g^{\prime}$ and data not shown) and a marked decrease in MF sprouts in the stratum infrapyramidale (Fig. $6 h^{\prime}$, arrows), similar to the pattern observed for wild-type mice treated identically. This phenotype confirms and extends our cell culture and in vivo data. We conclude that PLD1 functions upstream of $\mathrm{tPA}$ in the regulation of neurite growth.

In summary, our in vivo studies demonstrate that there is a positive correlation between levels of neuronal PLD1 and both wild-type mice

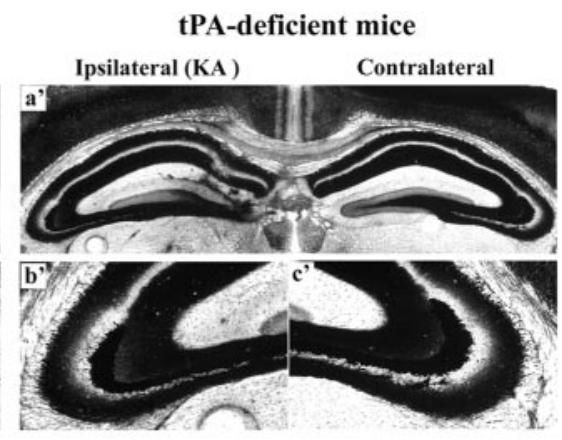

tPA-deficient mice
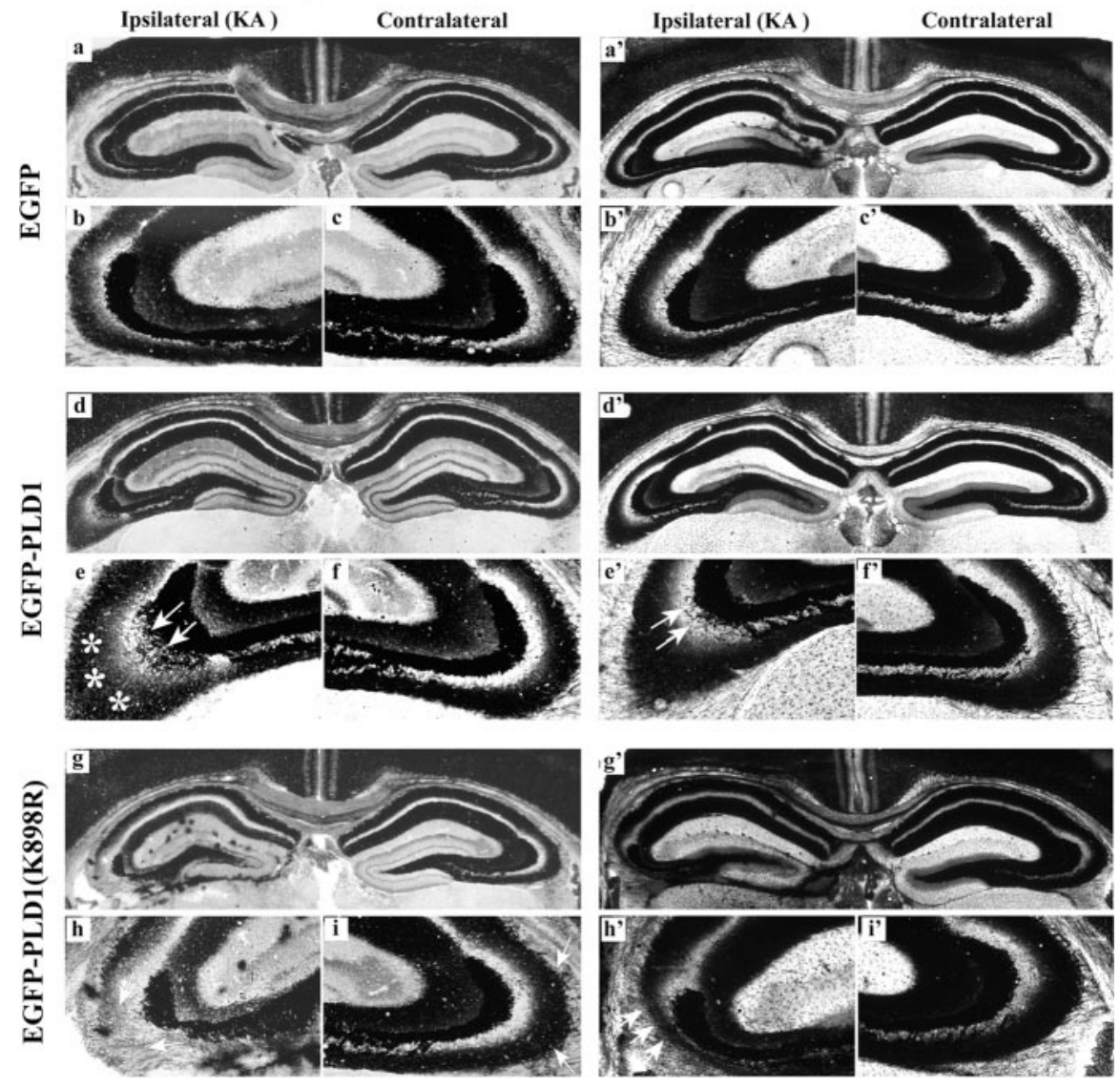
in CA3 MF sprouting at day 15 with neuronal overexpression of wild-type and catalytically inactive
mice were given injections of $1.5 \mathrm{nmol}$ of kainate into the amygdala unilaterally. In parallel, viral vectors encoding PLD1 [wild type $(\boldsymbol{d}-\boldsymbol{f}) ; \mathrm{tPA}$
$\mathrm{tPA}^{-I-}\left(\boldsymbol{g}^{\prime}-\boldsymbol{i}^{\prime}\right)$ ] were delivered into the DG on the kainate-injected side via mini-osmotic pumps (labeled as ipsilateral). Infusion of EGFP vector served as a negative control [wild type $(\boldsymbol{a}-\boldsymbol{c}) ; \mathrm{tPA}-1-\left(\boldsymbol{a}^{\prime}-\boldsymbol{c}^{\prime}\right)$ ]. Mice were killed at day 15 , and the MF was visualized using Timm silver staining. MF sprouts are indicated by arrows or asterisks.

tPA secretion and MF outgrowth. Higher expression of active PLD1 in DG neurons of the wild-type mice elicits more prominent MF sprouting in the DG locally and in the spatially removed CA3 region. In contrast, mice expressing the inactive PLD1 are characterized by aberrantly sprouted blunt MF in the DG and fewer sprouts in CA3.

\section{Discussion}

Extracellular tPA makes a major contribution to neuroplasticity by remodeling cell-cell and cell-matrix contacts in the path of the advancing growth cone (Krystosek and Seeds, 1981; Pittman, 1985; Wu et al., 2000). The active protease is synthesized and stored in vesicles in neurons. Secretion of tPA can be triggered rapidly by increased neuronal activity. Regulated tPA release has been demonstrated in chromaffin cells (Parmer et al., 1997, 2000; Lochner et al., 1998). In these cells, tPA is presumably targeted to catecholamine storage vesicles and coreleases with catecholamines after stimulation, based on subcellular fractionation methods and secretagogue-release assays. Lochner et al. (1998) generated direct evidence for the vesicular localization of tPA in rat pheochromocytoma PC12 cells. A tPA/GFP hybrid protein was expressed in PC12 cells, and its subcellular distribution and dynamics were monitored through real-time imaging of the green fluorescent labeling. They found that tPA/GFP was packed in intracellular vesicles and transported toward the growth cone 


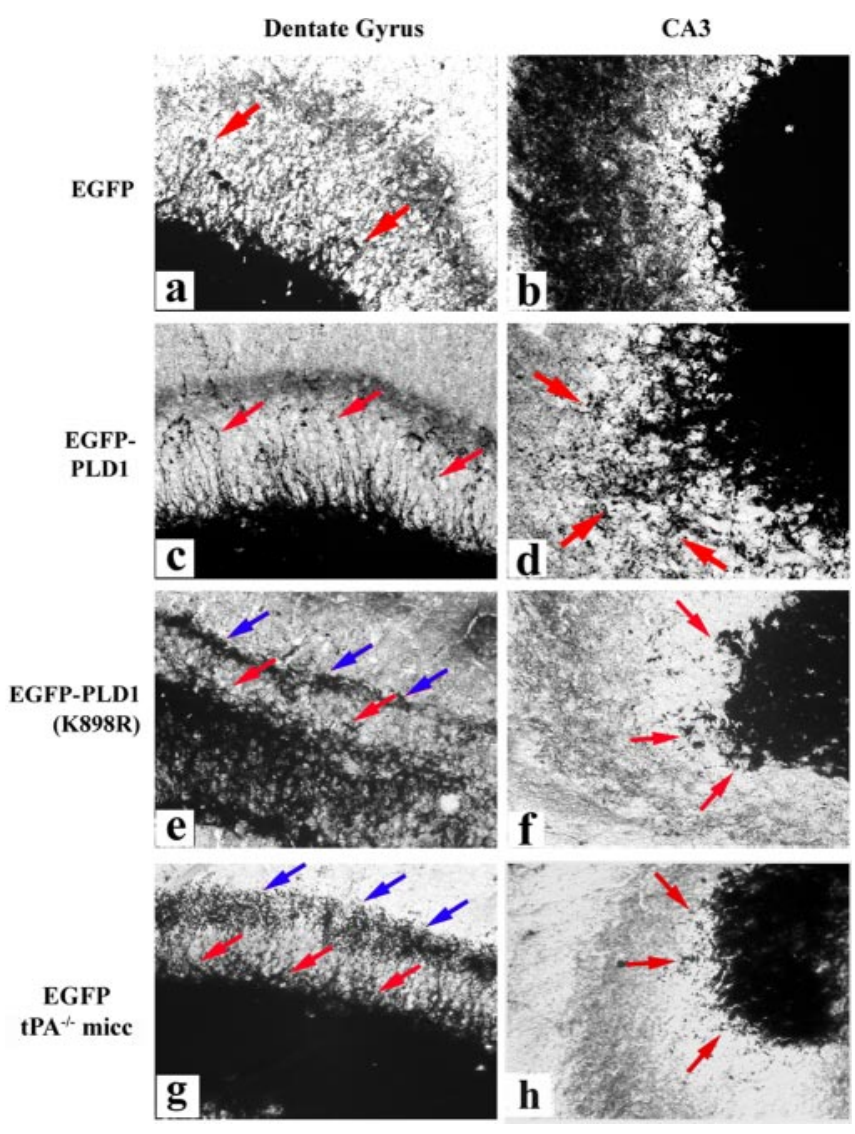

Figure 7. Gain- and loss-of-function changes, respectively, in DG and CA3 MF sprouting at day 15 as a consequence of CNS overexpression of wild-type and catalytically inactive PLD1. Higher-magnification images of selected regions in Figure 6 are shown. MF sprouts and boutons are indicated by red arrows. Blue arrows denote the abnormal laminar band of Timm staining observed in wild-type mice expressing inactive PLD1 and in $\mathrm{PPA}^{-1-}$ mice at the border separating the molecular and granular cell layers.

Table 1. Quantification of MF outgrowth in mice expressing the wild-type or mutant PLD1 allele

\begin{tabular}{llc}
\hline Hippocampal subfield & Treatment & Timm index \\
\hline DG & EGFP & $99.57 \pm 10.46$ \\
& EGFP-PLD1 & $166.32 \pm 10.62^{*}$ \\
& EGFP-PLD1(K898R) & $107.41 \pm 13.99$ \\
CA3 & EGFP & $110.3 \pm 10.07$ \\
& EGFP-PLD1 & $163.86 \pm 11.45^{*}$ \\
& EGFP-PLD1(K898R) & $68.43 \pm 7.96^{*}$ \\
\hline
\end{tabular}

Hippocampal MFs in wild-type mice were assessed by Timm stain as shown in Figures 6 and 7 . Timm granules were measured in the DG and CA3 regions using the Scion software and normalized by surface area (and length of the DG), as described by Zheng et al. (1998). Results are presented as mean \pm SD ( $n=5$ for each group). Data from the EGFP-PLD1 and EGFP-PLD1 (K898R) groups are both compared with the EGFP control group. * $p<0.01$.

of the axon from the somata. The distribution pattern of the hybrid protein resembled the immunocytochemical staining pattern of endogenous tPA. In addition to these in-culture data, it was demonstrated (Gualandris et al., 1996) that in the mouse hippocampus, neuronal tPA was secreted after calciumdependent membrane depolarization. However, little is known about the molecular mechanisms underlying the regulatory process of tPA release. Leprince et al. (1996) reported that release of tPA and the induction of short neurite growth by differentiating PC12 cells are affected by modulation of protein kinase A and protein kinase $\mathrm{C}$ (PKC) activity. $\mathrm{PKC}$ is a potent activator of PLD activity (Frohman et al., 1999). Other researchers have shown that PLD is involved in both the secretory pathway and neurite
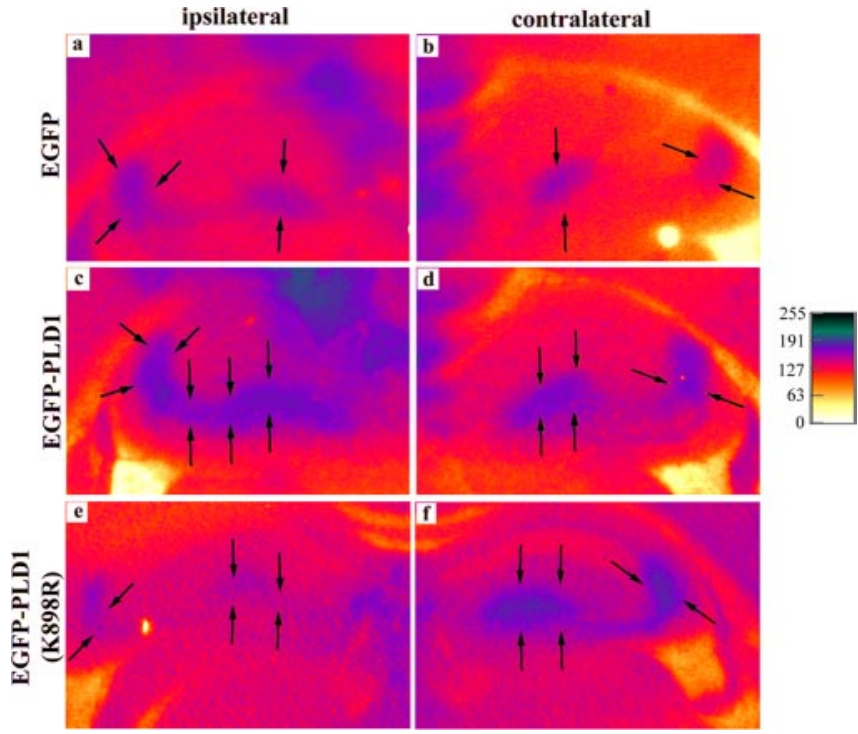

Figure 8. Regulation of TPA secretion by PLD1 as a consequence of kainate challenge at day 7. In situ zymography was performed on $30 \mu \mathrm{m}$ coronal brain sections from wild-type mice killed at day 7 after unilateral viral infusion and kainate injection (labeled as ipsilateral; the untreated side is marked as contralateral). The grayscale image was converted to pseudocolor for better visualization of the zymography images, and the intensity scale bar is shown on the right. The blue area outlined by arrows indicates the presence of tPA activity. An enhanced level of secreted tPA was detected on the side with elevated neuronal expression of active PLD1 ( $\boldsymbol{c}$, arrows) compared with either the contralateral hippocampus of the same mouse (d, arrows) or that of the SIN-EGFP-infused hippocampus ( $\boldsymbol{a}$, arrows). In contrast, tPA activity was diminished in the hippocampus expressing inactive PLD1 (e, arrows) compared with either the contralateral side ( $\boldsymbol{f}$, arrows indicating basal tPA activity) or control animals ( $\boldsymbol{a}$, arrows).

growth. For example, PLD1 has been clearly linked to regulation of secretion and secretory granule exocytosis in a variety of cell types, including neurons (Chen et al., 1997; Vitale et al., 2001; Choi et al., 2002). Vitale et al. (2001) demonstrated that, in neuroendocrine cells, overexpressed PLD1 increases secretagoguestimulated exocytosis, whereas catalytically inactive PLD1 inhibits it. Similarly, Humeau et al. (2001) described that injection of catalytically inactive PLD1 protein inhibits acetylcholine release by $>90 \%$ in Aplysia neurons, suggesting that PLD1 regulates a rate-limiting step of exocytosis in that setting. In most cases, the catalytically inactive PLD mutant is able to partially inhibit PLDdependent biological events (Vitale et al., 2001), presumably by competing with endogenous PLD for inclusion into the protein complexes that mediate the process. This effect is obtained when high levels of overexpression of the inactive allele are achieved. Although the catalytically inactive protein is frequently not a very effective dominant negative, several other approaches have been used here and elsewhere in model systems to examine the role of the endogenous protein, including pharmacological inhibitors (ceramide, alcohol) and overexpression of a PLD activator, ARF6, to stimulate endogenous PLD1 (or inhibit it, with use of the inactive ARF6 mutant allele) (Vitale et al., 2002). Although all of these approaches have caveats, results supporting of a role for endogenous PLD1 in regulated exocytosis were obtained in each case.

For PLD to directly influence tPA secretion, it should be present in the cell that releases the tPA. In the CNS, tPA is made by two cell types, neurons and microglia (Strickland et al., 1996). Given that we found preferential expression of PLD1 by neurons and PLD2 by astrocytes (Zhang et al., 2004), we thus focused on the potential role of PLD1 on PA secretion from neurons.

In cultured mouse hippocampal neurons, we demonstrated 
that PLD1 substantially enhanced tPA secretion induced by either forskolin or $\mathrm{Ca}^{2+}$ ionophore in an activity-dependent manner. This effect was primarily attenuated by the addition of 1-butanol, which also suppressed stimulated tPA release from control neurons not expressing the exogenous PLD1 gene, suggesting an involvement of endogenous PLD in TPA release. These findings indicate that neuronal PLD1 is a vital component in the pathway controlling tPA secretion. The facilitated tPA release was accompanied by exaggerated neurite extension, suggesting a physiological relevance to the regulation of tPA secretion by PLD1, and this was confirmed in the in vivo setting using a model for epilepsy well known to elicit (MF) neurite extension in the DG.

Several mechanisms have been proposed by us and others regarding how PLD might regulate secretory machinery and/or neurite outgrowth. First, PA, which is generated by PLD at the plasma membrane, is a multifunctional lipid that can be further metabolized to other important signaling lipids such as diacylglycerol and lysophosphatidic acid. In addition, it can activate other signaling enzymes (Honda et al., 1999), facilitate membrane vesicle fusion events (Vitale et al., 2002), or serve as a lipid anchor for membrane-associating proteins (Rizzo et al., 2000). Second, PLD is thought to promote sustained activation of PKC through the generation of PA and possibly diacylglycerides, both of which stimulate PKC. PLD could thus promote secretion, because activation of PKC along with an increase in cytosolic free calcium are essential signals for secretion in many cell types, including hippocampal neurons (Ruehr et al., 1997). Third, a mechanism that links neurite outgrowth and vesicle trafficking is the idea that to extend neurites, cells need to synthesize, reorganize, and transport phospholipids to the plasma membrane. PC, the substrate of PLD, is the most abundant phospholipid in mammalian biological membranes. Thus, PLD might be required for replenishing lipid components of the plasma membrane during neuroplastic remodeling.

How would PLD become activated in this setting? It has been reported that stimulation of metabotropic glutamate receptors by glutamate results in increased PLD activity in the rat hippocampus (Holler et al., 1993; Attucci et al., 2001). Glutamate is the primary amino acid neurotransmitter in the hippocampal MF pathway (Henze et al., 2000). tPA is known to mediate MF sprouting (Wu et al., 2000). Therefore, it is possible that after stimulation, increased levels of glutamate would activate PLD, which in turn would promote tPA release, leading to MF sprouting.

In this study, we describe a novel regulatory mechanism underlying neuronal tPA secretion during axonal sprouting that could be manipulated to modify the course of neurite growth and subsequent pathophysiological changes.

\section{References}

Agapov E, Frolov I, Lindenbach B, Pragai B, Schlesinger S, Rice C (1998) Noncytopathic Sindbis virus RNA vectors for heterologous gene expression. Proc Natl Acad Sci USA 95:12989-12994.

Attucci S, Torregrossa S, Moroni F, Giampietro D (2001) Metabotropic glutamate receptors stimulate phospholipase $\mathrm{D}$ via different pathways in the adult and neonate rat hippocampus. Neurochem Res 26:1151-1155.

Baranes D, Lederfein D, Huang Y, Chen M, Bailey C, Kandel E (1998) Tissue plasminogen activator contributes to the late phase of LTP and to synaptic growth in the hippocampal mossy fiber pathway. Neuron 21:813-825.

Buckmaster P, Zhang G, Yamawaki R (2002) Axon sprouting in a model of temporal lobe epilepsy creates a predominantly excitatory feedback circuit. J Neurosci 22:6650-6658.

Chen B, Lendvai B, Nimchinsky E, Burbach B, Fox K, Svoboda K (2000) Imaging high-resolution structure of GFP-expressing neurons in neocortex in vivo. Learn Mem 7:433-441.
Chen YG, Siddhanta A, Austin CD, Hammond SM, Sung TC, Frohman MA, Morris AJ, Shields D (1997) Phospholipase D stimulates release of nascent secretory vesicles from the trans-Golgi network. J Cell Biol 138:495-504.

Choi WS, Kim YM, Combs C, Frohman MA, Beaven MA (2002) Phospholipase D1 and 2 regulate different phases of exocytosis in mast cells. J Immunol 168:5682-5689.

Cockcroft S (2001) Signalling roles of mammalian phospholipase D1 and D2. Cell Mol Life Sci 58:1674-1687.

Colley WC, Altshuller YM, Sue-Ling CK, Copeland NG, Gilbert DJ, Jenkins NA, Branch KD, Bollag RJ, Bollag WB, Frohman MA (1997) Cloning and expression analysis of murine phospholipase D1. Biochem J 326:745-753.

D’Apuzzo M, Mandolesi G, Reis G, Schuman E (2001) Abundant GFP expression and LTP in hippocampal acute slices by in vivo injection of Sindbis virus. J Neurophysiol 86:1037-1042.

Du G, Huang P, Liang BT, Frohman MA (2004) Phospholipase D2 localizes to the plasma membrane and regulates angiotensin II receptor endocytosis. Mol Biol Cell 15:1024-1030.

Engel JJ, Williamson PD, Wieser H-G (1997) Mesial temporal lobe epilepsy. In: Epilepsy: a comprehensive textbook (Engel Jr JPT, ed), pp 2417-2426. Philadelphia: Lippincott-Raven.

Franklin K, Paxinos G (1997) The mouse brain in stereotaxic coordinates. Orlando, FL: Academic.

Frohman MA, Sung TC, Morris AJ (1999) Mammalian phospholipase D structure and regulation. Biochim Biophys Acta 1439:175-186.

Garcia-Rocha M, Avila J, Armas-Portela R (1994) Tissue-type plasminogen activator (tPA) is the main plasminogen activator associated with isolated rat nerve growth cones. Neurosci Lett 180:123-126.

Gibbs TC, Meier K (2000) Expression and regulation of phospholipase D isoforms in mammalian cell lines. J Cell Physiol 182:77-87.

Gualandris A, Jones T, Strickland S, Tsirka S (1996) Membrane depolarization induces calcium-dependent secretion of tissue plasminogen activator. J Neurosci 16:2220-2225.

Hayakawa K, Nakashima S, Ito Y, Mizuta K, Miyata H, Nozawa Y (1999) Increased expression of phospholipase D1 mRNA during cAMP- or NGFinduced differentiation in PC12 cells. Neurosci Lett 265:127-130.

Henze D, Urban N, Barrionuevo G (2000) The multifarious hippocampal mossy fiber pathway: a review. Neuroscience 98:407-427.

Holler T, Cappel E, Klein J, Loffelholz K (1993) Glutamate activates phospholipase $\mathrm{D}$ in hippocampal slices of newborn and adult rats. J Neurochem 61:1569-1572.

Holm I, Geneser F (1991) Histochemical demonstration of zinc in the hippocampal region of the domestic pig. III. The dentate area. J Comp Neurol 308:409-417.

Honda A, Nogami M, Yokozeki T, Yamazaki M, Nakamura H, Watanabe H, Kawamoto K, Nakayama K, Morris AJ, Frohman MA, Kanaho Y (1999) Phosphatidylinositol 4-phosphate 5-kinasea is a downstream effector of the small G protein ARF6 in membrane ruffle formation. Cell 99:521-532.

Hughes WE, Elgundi Z, Huang P, Frohman MA, Biden TJ (2004) Phospholipase D1 regulates secretagogue-stimulated insulin release in pancreatic beta-cells. J Biol Chem 279:27534-27541.

Humeau Y, Vitale N, Chasserot-Golaz S, Dupont L, Du G, Frohman MA, Bader M-F, Poulain P (2001) A role for phospholipase D1 in neurotransmitter release. Proc Natl Acad Sci USA 98:15300-15305.

Krystosek A, Seeds N (1981) Plasminogen activator release at the neuronal growth cone. Science 213:1532-1534.

Leprince P, Bonvoisin C, Rogister B, Mazy-Servais C, Moonen G (1996) Protein kinase- and staurosporine-dependent induction of neurite outgrowth and plasminogen activator activity in PC12 cells. Biochem Pharmacol 52:1399-1405.

Liscovitch M, Czarny M, Fiucci G, Tang X (2000) Phospholipase D: molecular and cell biology of a novel gene family. Biochem J 345:401-415.

Lochner J, Kingma M, Kuhn S, Meliza C, Cutler B, Scalettar B (1998) Realtime imaging of the axonal transport of granules containing a tissue plasminogen activator/green fluorescent protein hybrid. Mol Biol Cell 9:2463-2476.

Mamoon A, Smith J, Baker R, Farley J (1999) Activation of protein kinase A increases phospholipase D activity and inhibits phospholipase D activation by acetylcholine in tracheal smooth muscle. J Pharmacol Exp Ther 291:1188-1195. 
McDermott M, Wakelam MJ, Morris AJ (2004) Phospholipase D. Biochem Cell Biol 82:225-253.

Min D, Ahn B, Rhie D, Yoon S, Hahn S, Kim M, Jo Y (2001) Expression and regulation of phospholipase D during neuronal differentiation of PC12 cells. Neuropharmacology 41:384-391.

Nicole O, Docagne F, Ali C, Margaill I, Carmeliet P, MacKenzie E, Vivien D, Buisson A (2001) The proteolytic activity of tissue-plasminogen activator enhances NMDA receptor-mediated signaling. Nat Med 7:59-64.

Niquet J, Jorquera I, Ben-Ari Y, Represa A (1993) NCAM immunoreactivity on mossy fibers and reactive astrocytes in the hippocampus of epileptic rats. Brain Res 626:106-116.

Parent JM, Lowenstein DH (1997) Mossy fiber reorganization in the epileptic hippocampus. Curr Opin Neurol 10:103-109.

Parmar P, Coates L, Pearson J, Hill R, Birch N (2002) Neuroserpin regulates neurite outgrowth in nerve growth factor-treated PC12 cells. J Neurochem 82:1406-1415.

Parmer R, Mahata M, Mahata S, Sebald M, O’Connor D, Miles L (1997) Tissue plasminogen activator (t-PA) is targeted to the regulated secretory pathway. Catecholamine storage vesicles as a reservoir for the rapid release of t-PA. J Biol Chem 272:1976-1982.

Parmer R, Mahata M, Gong Y, Mahata S, Jiang Q, O'Connor D, Xi X, Miles L (2000) Processing of chromogranin A by plasmin provides a novel mechanism for regulating catecholamine secretion. J Clin Invest 106:907-915.

Pellegrini-Giampietro D, Torregrossa S, Moroni F (1996) Pharmacological characterization of metabotropic glutamate receptors coupled to phospholipase D in the rat hippocampus. Br J Pharmacol 118:1035-1043.

Pittman R (1985) Release of plasminogen activator and calcium-dependent metalloprotease from cultured sympathetic and sensory neurons. Dev Biol 110:91-101.

Qian Z, Gilbert M, Colicos M, Kandel E, Kuhl D (1993) Tissue-plasminogen activator is induced as an immediate-early gene during seizure, kindling and long-term potentiation. Nature 361:453-457.

Represa A, Ben-Ari Y (1997) Molecular and cellular cascades in seizureinduced neosynapse formation. Adv Neurol 72:25-34.

Represa A, Tremblay E, Ben-Ari Y (1987) Kainate binding sites in the hippocampal mossy fibers: localization and plasticity. Neuroscience 20:739-748.

Rizzo MA, Shome K, Watkins SC, Romero G (2000) The recruitment of Raf- 1 to membranes is mediated by direct interaction with phosphatidic acid and is independent of association with Ras. J Biol Chem 275:23911-23918.

Rogove AD, Tsirka SE (1998) Neurotoxic responses by microglia elicited by excitotoxic injury in the mouse hippocampus. Curr Biol 8:19-25.

Royle S, Collins F, Rupniak H, Barnes J, Anderson R (1999) Behavioural analysis and susceptibility to CNS injury of four inbred strains of mice. Brain Res 816:337-349.

Ruehr M, Zhang L, Dorman R (1997) Lipid-dependent modulation of $\mathrm{Ca}^{2+}$ availability in isolated mossy fiber nerve endings. Neurochem Res 22:1215-1222.

Sallés F, Strickland S (2002) Localization and regulation of the tissue plasminogen activator-plasmin system in the hippocampus. J Neurosci 22:2125-2134.

Siao C, Fernandez S, Tsirka S (2002) Cell type-specific roles for tissue plasminogen activator released by neurons or microglia after excitotoxic injury. J Neurosci 23:3234-3242.

Siddiqi A, Srajer G, Leslie C (2000) Regulation of human PLD1 and PLD2 by calcium and protein kinase C. Biochim Biophys Acta 1497:103-114.

Skippen A, Jones DH, Morgan CP, Li M, Cockcroft S (2002) Mechanism of ADP ribosylation factor-stimulated phosphatidylinositol 4,5bisphosphate synthesis in HL60 cells. J Biol Chem 277:5823-5831.

Strickland S, Gualandris A, Rogove A, Tsirka S (1996) Extracellular proteases in neuronal function and degeneration. Cold Spring Harb Symp Quant Biol 61:739-745.

Sung J, Lee S, Min D, Eom T, Ahn Y, Choi M, Kwon Y, Chung K (2001) Differential activation of phospholipases by mitogenic EGF and neurogenic PDGF in immortalized hippocampal stem cell lines. J Neurochem 78:1044-1053.

Takahashi T, Svoboda K, Malinow R (2003) Experience strengthening transmission by driving AMPA receptors into synapses. Science 299:1585-1588.

Tsirka SE, Gualandris A, Amaral DG, Strickland S (1995) Excitotoxininduced neuronal degeneration and seizure are mediated by tissue-type plasminogen activator. Nature 377:340-344.

Verrall S, Seeds N (1988) Tissue plasminogen activator binding to mouse cerebellar granule neurons. J Neurosci Res 21:420-425.

Vitale N, Caumont-Primus A-S, Chasserot-Golaz S, Du G, Wu S, Sciorra VA, Morris AJ, Frohman MA, Bader M-F (2001) Phospholipase D1 : a key factor for the exocytotic machinery in neuroendocrine cells. EMBO J 20:2424-2434.

Vitale N, Chasserot-Golaz S, Bailly Y, Morinaga N, Frohman MA, Bader M-F (2002) Calcium-regulated exocytosis of dense core vesicles requires the activation of ARF6 by ARNO at the plasma membrane. J Cell Biol 159:79-89.

Wu YP, Siao C-J, Lu W, Sung T-C, Frohman MA, Milev P, Bugge TH, Degen JL, Levine J, Margolis RU, Tsirka SE (2000) The tPA/plasmin extracellular proteolytic system contributes to hippocampal mossy fiber reorganization through a novel proteoglycan substrate. J Cell Biol 148:1295-1304.

Zhang Y, Huang P, Du G, Kanaho Y, Frohman M, Tsirka S (2004) Increased expression of two phospholipase D isoforms during experimentally induced hippocampal mossy fiber outgrowth. Glia 46:74-83.

Zheng D, Butler L, McNamara J (1998) Kindling and associated mossy fibre sprouting are not affected in mice deficient of NGFI-AINGFI-B genes. Neuroscience 83:251-258. 